\title{
Spontaneous rupture of a pancreatic pseudocyst
}

\author{
Mark TP Mujer, Manoj P Rai, Varunsiri Atti, Shiva Shrotriya
}

Internal Medicine, Sparrow Hospital, Michigan State University, Lansing, Michigan, USA

\section{Correspondence to Dr Mark TP Mujer, mark.mujer@hc.msu.edu}

MTPM and MPR contributed equally.

Accepted 10 September 2018

\section{DESCRIPTION}

This is a case of a 50-year-old woman with medical history significant for chronic pancreatitis secondary to alcohol abuse who initially presented with a 3-week history of progressively worsening epigastric pain. The patient described the pain as sharp, radiating to the back, worsened with intake of both solid foods and liquids and relieved with self-induced emesis. On admission, the patient was hypertensive, but other vitals were within normal limits. The abdomen was soft; however, there is a firm palpable mass extending from the epigastric to the right and left upper quadrants. Labs were remarkable for hypokalaemia with potassium (K) 3 meq/L (normal range 3.5-4.9 meq/L), mildly elevated lipase $132 \mathrm{U} / \mathrm{L}(7-60 \mathrm{U} / \mathrm{L})$ and an elevated alkaline phosphatase of $164 \mathrm{U} / \mathrm{L}$ (41-108 U/L). CT of the abdomen with contrast (figures 1 and 2) showed a large cystic structure measuring $12.9 \times 21.2 \mathrm{~cm}$ directly adjacent to the body of the pancreas and a fluid collection with enhancing rim measuring $4.8 \times 6.6 \mathrm{~cm}$ near the pancreatic tail with subsequent displacement of the stomach. Gastroenterology recommended cyst-gastrostomy at a tertiary care centre. However, surgery recommended surgical cyst-gastrostomy in the facility. The patient was made nil per os and started on total parenteral nutrition. Patient declined pain medications. Four days after admission, the patient started complaining of sudden worsening of the abdominal pain. Abdomen examination remained unchanged from admission and no interval imaging studies were performed. The following day, the patient's abdomen became diffusely rigid and she developed tachycardia and

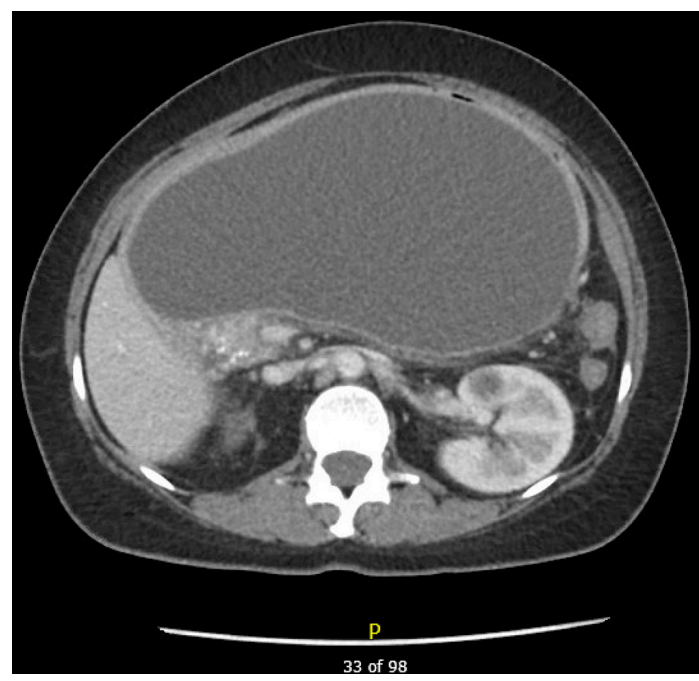

Figure $1 \mathrm{CT}$ of the abdomen (axial) with contrast showing a large cystic structure measuring $12.9 \times 21.2 \mathrm{~cm}$ directly adjacent to the body of the pancreas.

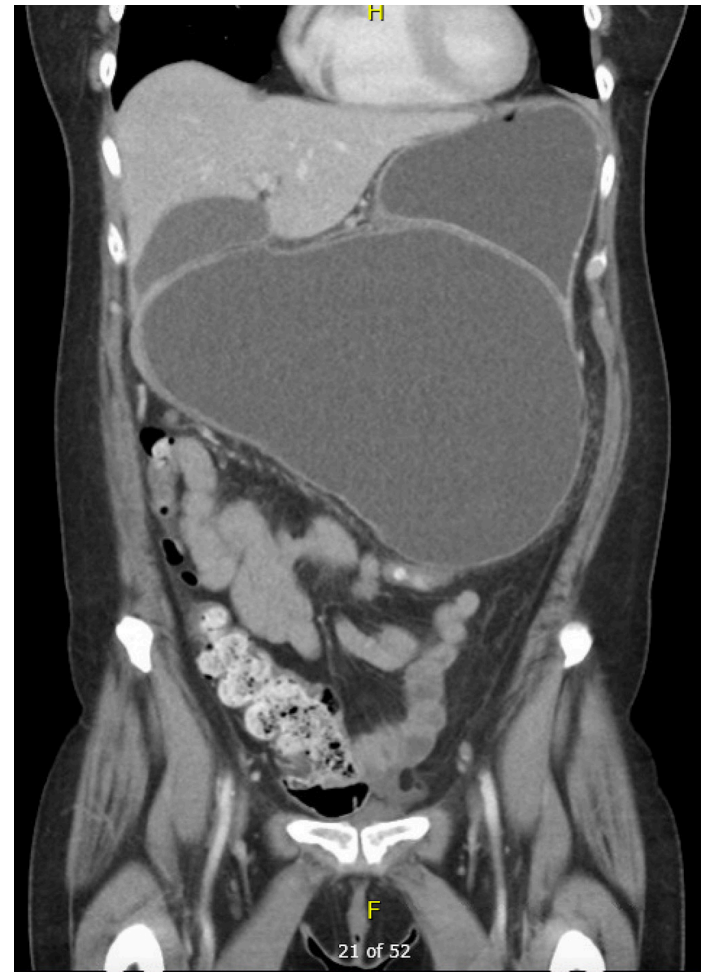

Figure 2 CT of the abdomen (coronal) with contrast showing a fluid collection with enhancing rim or thickened wall measuring $4.8 \times 6.6 \mathrm{~cm}$ near the pancreatic tail.

hypotension. Labs were remarkable for leucocytosis with rise in white cell count to $41.5 \times 10^{9} / \mathrm{L}$ $\left(4.0-12.0 \times 10^{9} / \mathrm{L}\right)$, acute kidney injury with rise in creatinine from 0.36 to $1.85 \mathrm{mg} / \mathrm{dL}(0.60-1.40 \mathrm{mg} /$ $\mathrm{dL})$, hyperkalaemia with K $6.5 \mathrm{meq} / \mathrm{L}$ and elevation of lactate to $3.5 \mathrm{mmol} / \mathrm{L}(0.2-1.8 \mathrm{mmol} / \mathrm{L})$. The patient was then started on piperacillin-tazobactam for empiric coverage. An emergent CT of the abdomen showed a decrease in the size of the pancreatic pseudocyst to $7.3 \times 13.6 \mathrm{~cm}$ and a large amount of ascites suggesting rupture of the pseudocyst into the abdominal cavity (figure 3 ). Patient was then taken for emergent exploratory laparotomy. On entering the abdomen, there was a large amount of ascitic fluid which was sucked out using a poolsucking device. About $3.5 \mathrm{~L}$ of abdominal fluid (light brownish, clear, fluid) was aspirated. There were some inflammatory flakes on the small bowel which were removed. There were inflammatory exudates in the pelvis and the suprahepatic region which were all washed out. There was a perforation noted in the pseudocyst about $3 \mathrm{~cm}$ just below the greater curvature of the stomach and between the transverse colon. The cavity could be easily seen and explored with the suction cannula. The fluid in the pseudocyst cavity was emptied. The colon was 


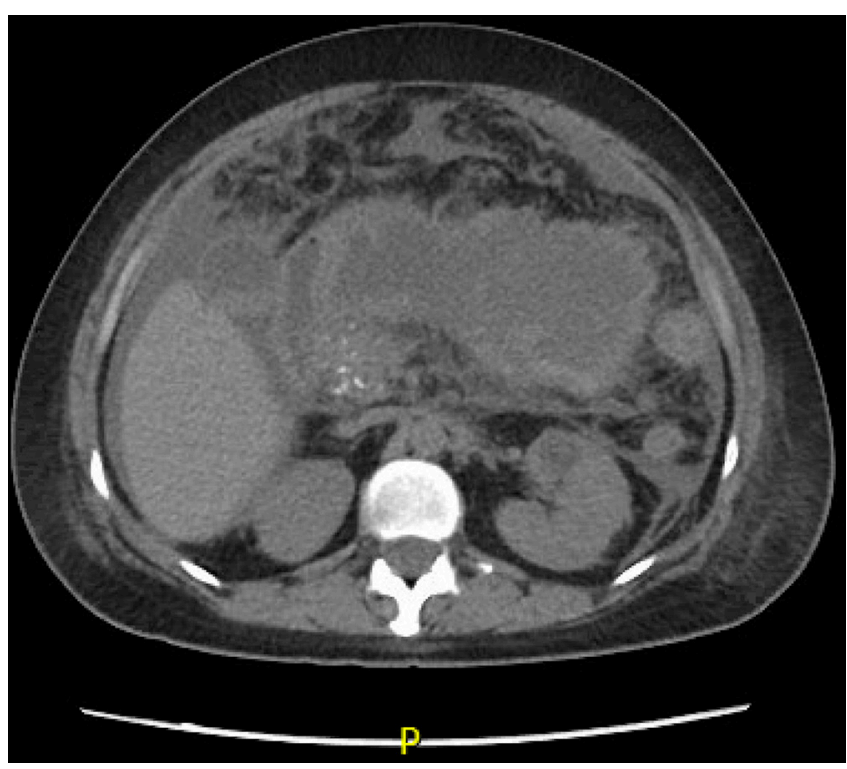

Figure 3 CT scan of the abdomen showing a decrease in the size of the pancreatic pseudocyst to $7.3 \times 13.6 \mathrm{~cm}$ and a large amount of ascites suggesting rupture of the pseudocyst into the abdominal cavity.

separated from the wall of the pseudocyst. A Roux-en Y cyst jejunostomy was then performed along with an abdominal wash out. A drain was left around the pancreatic cyst jejunostomy site. Patient was monitored, treated with antibiotics and made a full recovery without any other issues.

Pancreatic pseudocyst are localised fluid collections as a result of acute or chronic pancreatitis.

These structures are surrounded by fibrous and granulation tissue and contain fluid rich in amylase and other pancreatic enzymes. The pseudocysts appear to arise from an insult to the pancreatic duct leading to extravasation of pancreatic secretions. Pseudocysts occur in 25\% of patients with chronic pancreatitis and has been observed more commonly in alcohol aetiology. Large pseudocysts can cause compression of adjacent structures leading to various complications and will warrant aggressive management. In a longitudinal study by Mehta et al, cyst $>7.5 \mathrm{~cm}$ or $>250 \mathrm{~mL}$ needs either surgical or endoscopic intervention. ${ }^{1}$ Spontaneous rupture of pancreatic pseudocysts has been reported in $<5 \%$ of cases. Approximately, half of these empty into the free peritoneal or pleural cavity, portal or splenic vein; the other half into an adjacent hollow viscus including the oesophagus, stomach, duodenum, small intestine, colon and renal pelvis.

Pseudocyst rupture into the hollow gastrointestinal tract may lead to spontaneous regression; however, rupture into the intra-abdominal cavity may result in peritonitis. Even though the exact mechanism of pancreatic pseudocyst rupture is unknown, several factors contribute to an increased risk: progressive digestion of the cyst wall by proteolytic enzymes activated by enterokinase, increased intra-abdominal pressure and minor abdominal trauma. The presence of high concentration of enzymes such as lipase, amylase and other proteolytic enzymes can lead to invasion into adjacent structures. ${ }^{2}{ }^{3}$ Alternatively, erosion into an adjacent vessel may cause intravascular thrombosis. ${ }^{24}$

\section{Learning points}

- Pancreatic pseudocyst rupture is a rare complication that may warrant immediate surgical intervention if it causes signs of peritonitis.

- A sudden increase in abdominal pain with or without signs of peritonitis warrants further investigation to rule out possible pseudocyst rupture.

- Pancreatic pseudocysts which rupture into hollow organs may resolve spontaneously without causing any complications.

Contributors MM and MPR contributed equally to writing the manuscript. VA and SS revised the manuscript.

Funding The authors have not declared a specific grant for this research from any funding agency in the public, commercial or not-for-profit sectors.

Competing interests None declared.

\section{Patient consent Obtained.}

Provenance and peer review Not commissioned; externally peer reviewed.

\section{REFERENCES}

1 Mehta R, Suvarna D, Sadasivan S, et al. Natural course of asymptomatic pancreatic pseudocyst: a prospective study. Indian J Gastroentero/ 2004;23:140-2.

2 Patidar Y, Sureka B, Singh VP, et al. Spontaneous rupture of intrahepatic pseudocyst into the inferior vena cava. Gastroenterol Rep 2016:gow011.

3 Procacci C, Mansueto GC, Graziani R, et al. Spontaneous rupture of a pancreatic pseudocyst into the portal vein. Cardiovasc Intervent Radiol 1995;18:399-402.

4 Dawson BC, Kasa D, Mazer MA. Pancreatic pseudocyst rupture into the portal vein. South Med J 2009;102:728-32.

Copyright 2018 BMJ Publishing Group. All rights reserved. For permission to reuse any of this content visit

http://group.bmj.com/group/rights-licensing/permissions.

BMJ Case Report Fellows may re-use this article for personal use and teaching without any further permission.

Become a Fellow of BMJ Case Reports today and you can:

- Submit as many cases as you like

- Enjoy fast sympathetic peer review and rapid publication of accepted articles

- Access all the published articles

- Re-use any of the published material for personal use and teaching without further permission

For information on Institutional Fellowships contact consortiasales@bmjgroup.com

Visit casereports.bmj.com for more articles like this and to become a Fellow 